\title{
Undergraduate Dissertations in Economics
}

\author{
Emeritus Professor Peter Smith
}

University of Southampton

First published 2009

Revised version July 2016

Printable PDF

\section{A Practical Guide}

For many students, the dissertation is the culmination of their undergraduate careers, and a rewarding and satisfying experience that gives them the opportunity to undertake an in-depth study of a topic that interests them. However, it can also become a traumatic and disillusioning venture for students who do not engage with the research, or who have a bad experience with some aspect of the dissertation process.

This chapter sets out to share good practice and provide guidance for co-ordinators, curriculum planners and supervisors, highlighting danger areas and providing discussion of some of the more contentious aspects of the dissertation process.

\section{Introduction}

A key aim of any honours degree programme in the UK is to encourage students to become independent learners. This is no easy task in an environment in which many students arrive from school or college with preconceived notions of what is meant by study, and an array of expectations about the support they will receive from academic staff, not to mention the feedback and interaction with staff that they can expect.

The Quality Assurance Agency (QAA) in August 2008 set out the Frameworks for Higher Education Qualifications in England, Wales and Northern Ireland, which contains the following descriptor for a Bachelor's degree with honours:

'Bachelor's degrees with honours are awarded to students who have demonstrated:

- a systematic understanding of key aspects of their field of study, including acquisition of coherent and detailed knowledge, at least some of which is at or informed by, the forefront of defined aspects of a discipline

- an ability to deploy accurately established techniques of analysis and enquiry within a discipline

- conceptual understanding that enables the student:

$\circ$ to devise and sustain arguments, and/or to solve problems, using ideas and techniques, some of which are at the forefront of a discipline 
- to describe and comment upon particular aspects of current research, or equivalent advanced scholarship, in the discipline

- an appreciation of the uncertainty, ambiguity and limits of knowledge

- the ability to manage their own learning, and to make use of scholarly reviews and primary sources (e.g. refereed research articles and/or original materials appropriate to the discipline).'

(Source:

http://www.qaa.ac.uk/en/Publications/Documents/Framework-Higher-Education-Qualifications08.pdf )

In the context of an economics programme, where in many cases students can arrive at university with no prior knowledge of the discipline, it is ambitious to think that students will be able to use ideas and techniques 'at the forefront' of the discipline after only three years of study, especially if this is really to be the aim for all honours students. On many programmes, the dissertation has become the prime vehicle by which students find an opportunity to become independent learners and to confront current research. For many students, the dissertation is the culmination of their undergraduate careers, and a rewarding and satisfying experience that gives them the opportunity to undertake an in-depth study of a topic that interests them. However, it can also become a traumatic and disillusioning venture for students who do not engage with the research, or who have a bad experience with some aspect of the dissertation process.

This chapter sets out to share good practice and provide guidance for co-ordinators, curriculum planners and supervisors, highlighting danger areas and providing discussion of some of the more contentious aspects of the dissertation process.

After a brief investigation of the current experience in the UK, this chapter is organised around the typical life-cycle of a dissertation, divided into a series of stages:

- laying the foundations

- topic selection

- early practicalities

- supervision

- progress monitoring

- data issues

- dissertation structure

- submission

- assessment

- academic integrity.

\section{The UK experience}

As background to this chapter, a brief email survey was undertaken to gather information about the role of the undergraduate dissertation in economics departments across the UK. A report on this survey may be found in Appendix 1. 
From the survey it seems that dissertations are a part of the majority of Economics programmes in the UK. However, there are significant differences in the way in which the dissertation module is organised, and the way that students experience the dissertation.

A particular issue is whether all students should be required to complete a dissertation as part of their undergraduate programme. In some institutions, the dissertation is indeed compulsory for everyone, but elsewhere it is restricted to single honours students, or to those students who obtain an average of $60 \%$ or more in their second year. The QAA's descriptor quoted above suggests that all students should receive some exposure to research, but clearly joint honours students are likely to find this more challenging than the specialists, having acquired less indepth familiarity with either of their chosen disciplines.

Where joint honours students are required to take the dissertation, it may be necessary to adjust the expectations in terms of content. For example, whilst a single honours student with some exposure to econometrics may be expected to undertake some empirical work, it would be unreasonable to expect a joint honours (e.g. Politics and Economics) student to have the same familiarity with econometric methods. It has been known for students to try to teach themselves econometrics, which can prove disastrous.

Whether the dissertation should be limited to the better students is a moot point. On the one hand, it could be argued that weaker students should have equal access to the dissertation option; it may even be that there are some students who may achieve a better result on the dissertation where they can immerse themselves in a topic and produce a polished piece of work, than they could produce under examination conditions or in a problem-set-oriented assessment. On the other hand, experience suggests that weaker students require more supervision, and are more likely to resort to practices that breach academic integrity guidelines.

For these reasons, it may be necessary (or desirable) to provide alternative ways of exposing joint honours and weaker students to research methods. This will be discussed later in section 4 .

Where the dissertation is compulsory for all students, the organisation of the module causes concern. When there are large numbers of students requiring supervision, the load on individual staff members becomes heavy - especially given that some topic areas (and some staff members) tend to be more popular with students than others. It may then be necessary to find some way of spreading the supervision load across available staff or accommodating differences through a workload management system. Spreading the load evenly may result in inconsistency in the supervision provided, which can be very difficult to monitor effectively.

Another major impact on the dissertation has been the rise of the internet, and the ease with which students are able to find material. This can lead to excessive reliance on sites such as Wikipedia, and makes it imperative to be able to monitor standards of academic integrity. Almost all of the survey respondents reported using TurnitinUK, whether as routine for all dissertations submitted, for a random sample or for suspect cases. The traditional remedy of holding vivas for all student dissertations becomes extremely costly when large numbers of students are involved (one institution reported that more than 500 dissertations are submitted in a 
typical year). Nonetheless, this practice appears to have survived in some economics departments.

\section{The dissertation life-cycle}

\subsection{Laying the foundations}

There is a sense in which the whole of learning and teaching in a programme can be seen as preparation for the dissertation, as it provides the opportunity for students to draw holistically upon the range of material that they have studied during their programme. However, the dissertation is a very different exercise from anything else that they will have been required to undertake and specific preparation is needed.

First, some training in research skills will need to be provided. This may or may not take place as part of a specific module within the programme that is devoted to preparation for the dissertation, perhaps in the penultimate year of study. This needs to include general discussion of research in economics, and the ways in which economists undertake research and scholarship. It is important to remember that this is likely to be a wholly new experience for most students, who may be well drilled in problem solving and mathematical exercises, but who may not have had much exposure to the practicalities of economic research.

The booklets by Greenlaw (2006) and Neugeboren (2005) may be useful references for students at this stage of the process, or they may wish to visit the "Doing a dissertation" tab of the Studying Economics website run by the Economics Network.

Included in this research training it is important to provide some guidance in library skills and the use of evidence in economics research. Being able to evaluate evidence, to weigh up the importance of a set of results and to be aware of the limitations of the evidence produced are challenging skills for students to develop.

There are different approaches to providing such research methods training. It may be that library staff will be able to provide sessions in library skills. It may be wise to incentivise students by awarding a small percentage of the dissertation marks for a library skills exercise. For example, students could be required to undertake an online literature search related to their chosen topic and produce a preliminary reading list. This has the added benefit for forcing them to start their research at an early stage of proceedings.

Depending on programme structure, some students may have had extensive exposure to statistical and econometric methods, so may be accustomed to handling data and interpreting results. However, there may still be a difference between running some regressions in response to a specific exercise during an econometrics module and devising a model to allow testing of a specific hypothesis.

Where students have not been exposed to econometrics, this will clearly affect the scope and nature of research that they can undertake. It may be that they are restricted to a theoretical 
approach or a literature review style of project, or that they need to find alternative ways of presenting evidence. Where there is a mixture of single and joint honours students it may well be that there are students working on similar topic areas, some of whom know some econometrics and others not. This can create particular pressures on the joint honours students, who may feel obliged to try to use techniques with which they are unfamiliar. This is almost always disastrous. It also becomes important that the skills base of students is taken into account during the assessment process, so that students without training in econometrics are not unduly penalised by markers.

It is increasingly crucial to provide clear guidance on academic integrity at an early juncture. Section 3.10 explores this issue in more depth.

Where there are large numbers of international students, support may need to be provided in academic writing. Indeed, such support may be necessary more generally, given that so many economics assessments are based on problem sets and exercises, rather than on extended continuous prose. There is some evidence that the writing skills of UK students may also need to be further developed in this context.

\subsection{Topic selection}

From a student perspective, finding a topic for the dissertation is a critical step. One of the key strengths of the dissertation is its capacity to engage the student by arousing interest and motivating through a sense of discovery. However, it can also be a stressful part of the process, especially for some weaker students who may not have strong ideas about topics that might inspire interest, and who may be daunted by the prospect of undertaking the task. Failure to find the right topic can be a recipe for a weak dissertation that does not fulfil the intended outcomes.

When the numbers of students looking for dissertation topics are relatively small, then it may be that students can be left to choose their own topics - probably subject to the availability of an appropriate supervisor or the submission of a coherent research proposal. With large numbers of students, this laissez-faire approach may not be feasible.

An alternative approach is to provide students with a list of topics from which they can choose. These topics may be closely circumscribed, or may simply offer a general topic area, leaving the student to focus on a specific research question within that topic area.

The advantage of providing very general topics is that that it leaves the responsibility of formulating a specific research question with the student. This is a key part of research in economics, of course, so it is good (albeit challenging) for the student to have to think about how to go about it. It also has the benefit of giving the student ownership of the question to be investigated, which helps to provide motivation.

\section{Top tips: dissertation topics}

There are several ways in which students can find (or be allocated) the topic for their research. 


\section{Students find their own topic, and then look for a supervisor}

This may work where the number of students is limited, but may be more difficult to manage when numbers increase. Some staff members are likely to be overwhelmed with requests, especially if they happen to have taught popular second year modules.

Students may also congregate around topics of recent interest - the financial crisis, the impact of migration, or the economics of Brexit...

Others may delay thinking about their topic until it is too late, or may choose topics that prove to be impracticable.

\section{Staff declare topic areas in which they are prepared to supervise projects}

This seems to work for a number of institutions. Topics here may be defined broadly - labour economics, development economics, or monetary economics. This may also produce bunching around some staff members.

\section{A list of topic areas is provided}

This entails listing key areas of economics - public economics, behavioural economics etc. Students are then allocated a supervisor, where possible a supervisor with a specific interest in that area. Bunching can be ameliorated by not guaranteeing that the allocated supervisor will be an expert in that field. After all, at undergraduate level, detailed knowledge of the topic area may not be crucial.

\section{A list of topics is provided}

More specific titles could be provided, rather than general areas. Some staff may prefer this, but others may not. Too specific a topic may attract no students at all (there are only so many undergraduates burning to undertake research into theoretical issues in econometrics).

For example, a topic such as 'Child labour in less developed countries' offers wide scope for tackling the issue in different ways and different contexts. A more specific topic such as "Are household members altruistically linked? an examination based on the Mexican anti-poverty programme Progresa' is much more prescriptive, and may deter students.

There will always be students with fixed ideas about what they wish to research, and these should be accommodated where possible and plausible.

\section{Top Tip}

Where there are large numbers of students, topic choice can be handled online.

Students can submit their preferences through a webpage, and asked to specify their top four choices and rank them. Students can then be allocated to topics and supervisors, with no 
guarantee that they will get their first choice - depending on whether certain topics are oversubscribed.

It is helpful for students if a selection of past dissertations is made available to current students to provide some guidance on what is expected of them. However, if the same topics appear for too many successive years, there may be the obvious danger of plagiarism. Even where this does not extend to actual copying, there is the danger that students will simply adopt the same dissertation structure as used by previous students rather than working through this part of the process on their own.

\subsection{Some early practicalities}

Legislation impinges on the dissertation process, and students may all be required to complete risk assessments before they start their research. The impetus from this comes from Health and Safety legislation in place since 1992, and many universities require such assessments for undergraduate and postgraduate students undertaking research. The need for this is perhaps more obvious where students are carrying out experiments in the physical sciences, but may also be important in the social sciences. There may also be a need to seek ethics approval, especially where research involves the use of human subjects, for example, where students intend to undertake surveys or to conduct experiments using human participants.

Given that most economics dissertations tend to be desk studies that do not involve the use of human subjects, the bureaucracy may be viewed as superfluous. Nonetheless, compliance with the law is essential. This may be especially important where economics as a discipline is part of a wider School of Social Sciences. Sociologists who decide to interview local drug dealers as part of their dissertation research clearly face rather different risks and ethical issues than an economist who decides to estimate a consumption function from macro data.

Sample forms can be viewed in Appendix 2. The ethics form is designed for a School of Social Sciences. The expectation is that the vast majority of economics projects will qualify to skip from question 1 to question 15, thus minimising the paperwork whilst still complying with the demands of the legislation.

Given the requirements of the Data Protection Act, it is also advisable to ask students to give permission for their completed dissertations to be made available within the university for succeeding generations of students. This then allows a database of previous dissertations to be mounted on an internal website or a Virtual Learning Environment (VLE) such as Blackboard or Moodle.

It is also important at the outset to be absolutely clear about some aspects of the dissertation. In particular, students seem to get very exercised about word length. In many UK undergraduate economics programmes, the dissertation counts as a double module in the final year - for example, 15 ECTS, or a quarter of the assessment for the year. Given the importance of this piece of work (especially where the final year carries a heavy weight), it is probably appropriate for the dissertation to carry a word length of 7,500 to 10,000 words. Notice that this may depend on institutional demands set by your School, Faculty or at University level. 


\section{Top Tips on the word limit:}

- Be explicit from the start about what is included and not included in the word count. When students get near to submission time, the chances are that they will be hitting the limit, and will want to exclude as much as possible from the count. To remove ambiguity, it is wise to be clear.

- Provide a list of what can be omitted from the word count, for example:

- Title page

- Acknowledgements

- Abstract

- Table of contents

- Bibliography

- Figures (i.e. diagrams, maps)

- Tables of data

- Prohibit the widespread use of appendices - otherwise, students will simply carve chunks of material out of the main text and stash it away at the back in the hope that it will not count. Make it clear that appendices will be part of the word count (perhaps allowing some appendices to be exempt, e.g. raw data, with the express permission of the supervisor).

- Then state that everything else counts. Students will still find questions to ask (what about footnotes?), but if you have been explicit you will be on reasonably firm ground and you can point out that the rules are the same for everyone.

- In order to enforce the word limit, you will probably need to impose penalties for exceeding it. A sliding scale is probably best - say, 1 percentage point per 100 words (or part thereof) by which the dissertation exceeds the limit. This provides students with the incentive to learn to be selective and to avoid waffle in presenting their report. And it seems to work!

\subsection{Supervision}

The provision of good supervision is crucial to the success of the dissertation. In many institutions facing increasing student numbers, the amount of contact between staff and students on a one-to-one basis is in decline. Indeed, it may be that the supervision of the dissertation provides the single most important opportunity for students to interact on a personal basis with a member of the academic staff. Some students may be intimidated by this, but if the relationship works, it can be mutually rewarding as an educational experience.

As in many other areas of learning and teaching, it is important to manage student expectations of the supervision process. It is helpful for students to be told clearly what they can expect from their supervisor. This may be expressed in terms of an entitlement, rather than being left openended. Such an entitlement could be expressed in terms of a number of meetings that each student is entitled to have with their supervisor or it could be expressed in hours. Experience with operating such a system is that although some students may request assistance above their entitlement - and this need not be prohibited within the scheme - others may choose not to avail themselves of their full entitlement. In the context of encouraging students to become independent learners, it may not be desirable to insist that all students attend for a given number 
of sessions. It is this that makes the entitlement system an attractive way of specifying what is the normal expectation for supervisory contact.

Such an approach has the added benefit of helping to manage the supervisors' expectations of the process. Supervisors need to know what is expected of them in terms of reading drafts, marking, length and frequency of meetings, and so on. It is also crucial that both supervisors and students have the same expectations of what is involved. Being explicit about this is thus crucial for both groups.

Achieving consistency of supervision provision is one of the challenges, especially when large numbers of students are in need of supervision. Just as some students may need more help than others, it is also important to be aware that some supervisors may be more comfortable in the role than others, or more prepared (or able) to make themselves available.

It is also common for certain topic areas to be more popular than others - and for some supervisors to be more popular than others. If unregulated, this can lead to a situation in which some members of staff find that they have much heavier loads than their colleagues.

Some fair way of allocating supervisory responsibilities may thus be needed. One possibility is to ensure that supervisory loads are recognised as part of a workload management system, in which there is a trade-off between supervisory responsibilities and other forms of teaching contact. An alternative is to allocate loads evenly across available staff. This may require allocating students to topics that are not their first choice, or requiring supervisors to oversee topics of which they have little specialist knowledge. This needs to be monitored carefully to safeguard the student experience. However, at the undergraduate level, specialist knowledge of topic areas may be less crucial than at masters' or doctoral level.

There may be benefits from group supervision of students following similar topics, not only in terms of economies of scale, but also because the students may be able to learn from each other. Economies of scale may arise because much of the advice given to students will be common the central importance of economic analysis, the need for a literature review, the interpretation of evidence, how to avoid plagiarism and so on.

\section{Example}

At my university, each supervisor is responsible for between six and ten students. It may be highly time-consuming to meet each supervisee separately on a one-to-one basis, but there are some issues that can be readily communicated in group sessions, perhaps even in combination with a colleague supervising in similar topic areas.

A first meeting could take place early in the year, or at the end of the penultimate year, when students have been allocated their topics and supervisors. This would be a preliminary briefing meeting, to answer questions and concerns, highlight some key relevant readings and data sources, and explain how the supervision will be conducted. Some preliminary explanation of how to structure a good dissertation is also provided, together with some discussion of what is meant by academic integrity. 
At a second meeting each student could be asked to talk about their topic, outline their progress to date, identify their research question (if they have formulated it) and comment on any problem areas that they have encountered.

A third meeting could be held towards the end of the first term. By this time, students will have been required to submit an interim report, in which they sketch out their proposed research, including an explanation of their research question, and the methodology that they propose to use in order to investigate their question. This is an opportunity to provide feedback and progress to date, to suggest future directions and to identify potential problems.

A fourth meeting could be held towards the end of the second term. Before this meeting, you could invite each student to submit an extract from the first chapter, including their explanation of their research question. In the meeting, you could comment on writing styles and referencing, and provide an opportunity for questions. The importance of maintaining standards of academic integrity also needs to be stressed.

Students should also be encouraged to meet up on a one-to-one basis if they have questions that are specific to their own research.

In some institutions, this is taken one step further, through the provision of a whole module (normally in the second year) that deals with research methods. The economies of scale in doing this are even greater, of course, as one individual (or a relatively small number of staff) can provide the generic advice that all students need in approaching the dissertation. Such dedicated modules are not always popular with students, who may see the material as being fragmented and of little relevance to them at the time. In other words, they may need to be convinced that they really will need this material at a later stage. Such modules are not always popular with the staff either. They may not be appealing to teach, and also put pressure on the curriculum. When so much other material has to be covered in the second year, there may be a reluctance to use up a whole module on research methods that could have been used to provide more micro theory or econometrics.

\subsection{Early progress monitoring and the dangers of the last minute rush}

A frequent complaint about students undertaking undergraduate dissertations is that they leave everything until the last minute. The pressures of other coursework items and mid-term or midyear examinations may encourage students to devote their time to these, as the dissertation seems less urgent.

There are various ways of trying to encourage students to start work on their research early, and not to rely on a late rush. It may be worth drawing an analogy in early discussions with them. Few students would think of arriving at an exam with only a few minutes to go, and thus finding they have no time to answer the questions. So, why should they think they can fritter away their dissertation time and start work on it when it is too late to do it justice? 
However, as economists, we understand about incentives, and thus realise that exhortation alone will not suffice. We need to provide good incentives if we expect students to start work early.

One possibility is to require students to give a presentation of their intended research at an early stage of proceedings. This could be a presentation to their peers with a member of academic staff present. It would even be possible to designate a discussant for each presentation or for a small percentage of the overall mark to be attached to it. However, as soon as numbers begin to grow, this option begins to become very costly in time and effort. Ensuring consistency in the assessment becomes problematic - although if it is a very small percentage of the overall mark, this may be less crucial. If the presentation becomes more than a small percentage, then the logistics of enabling appropriate external examining becomes a potential issue.

An alternative is to introduce an interim report or research proposal that has to be submitted at an early stage. Again, attaching a modest percentage of the overall marks to this report has good incentive effects, and provides an early check to identify students that are not engaging with the process, or who have unrealistic grandiose plans for solving the world's problems in 10,000 words. It is also a good opportunity to provide formal feedback - an important consideration when the paucity of feedback is a common criticism emerging from questionnaire surveys.

It may be helpful to ask students to submit draft material (or even chapters) to provide a framework for discussion in supervisory meetings - and to do so before the meeting takes place. There is nothing worse than having a student arrive to discuss their work clutching their precious draft, only to find that the time is mainly spent in the supervisor reading it, rather than being able to discuss it. It should be made clear that this is not for the purpose of proof-reading, which is not the supervisor's responsibility. It may be worth setting a timetable for such discussions at the beginning of the year - which then forces the student into a regular schedule of work. Of course, your institution's rules may prohibit the reading of draft material. You may also think that it is possible to go too far in helping the student, as this may militate against encouraging independent work and time management. However, it can make for more productive supervisory meetings - and anything that highlights that you are providing feedback may pay dividends in national student surveys.

\subsection{Data issues}

The other task that must be tackled at an early stage is data hunting. Students embarking on empirical work - probably for the first time - almost always have over-optimistic views of the data that are likely to be available. Perhaps a student has been to a course in development economics that has stressed the importance of human capital formation in stimulating improvements in agricultural productivity. An interesting project might be to examine the effect of primary schooling on agricultural productivity in rural Zanzibar. Or to examine the effect of overseas assistance on the provision of health care in Papua New Guinea. Panic then sets in when it transpires that, with only a few weeks remaining, there are no data to be found.

Again, this is partly a question of managing student expectations - and of getting students to hunt for their data as early as possible. 
Of course, there is a time inconsistency problem here. We tell the students that they must look for data as soon as possible... but we also tell them that they should think about the underlying economics of their topic first, in order that they know what data they will require. Without this proviso, the danger of data-mining is high. Students told to look for data early may well see what they can find, run a few regressions and then see if they can find a theory that will match their results.

There is a lot of data readily available on the internet. This brings good and bad news. The good news is that there are more data accessible on a wide range of economic topics that students can readily obtain. This expands the range of topics on which they can undertake empirical work and they are aided and abetted in this by the software at their disposal to enable them to produce lots of results. The bad news is that the scope for doing foolish things and getting nonsense results is also much expanded. The ease of use of today's software makes it very easy to produce results that go way beyond the competence and understanding of the students. Indeed, a key part of the supervisor's role may be to rein in the over-enthusiastic student to ensure that the work undertaken is appropriate for the topic being investigated, and the reasonable ambition of the student given knowledge and understanding of statistical and/or econometric methodology. This reining in has to done in a sensitive way, so as not to discourage or dishearten. A fine line to tread.

\section{Top Tip}

Provide web links to the most relevant data sources.

Providing web links to key recommended data sources is wise. This can be accomplished through a dedicated dissertation webpage or VLE. The links can then be tailored to the needs of a particular cohort of students. There is also a helpful section on the Economics Network website that provides links to freely available data.

One obvious situation in which this can be an issue is where a student has received no training in econometrics, but has heard of 'regression' and perceives that no dissertation is complete without it. There may be some bright students out there who can teach themselves regression along the way and produce sensible results. But for every one such student, there are likely to be countless others who will be unable to produce coherent results. For the econometrically untrained, more modest objectives need to be set for the analysis of empirical data. However, the collection of data, and the marshalling of evidence in support (or not) of an hypothesis, is a central part of research in economics. In some cases, students may sign up for an optional course in econometrics for which they are ill-prepared. This has a doubly damaging impact, as they may fail the module as well as finding themselves no better off for the research.

Another pitfall is where a student with some econometric training collects data and runs some regressions, but is unable to produce results that are consistent with any known economic theory. Panic then sets in. Can economic theory really be so wrong? It takes confidence for a novice researcher to look at a set of seemingly meaningless results with equanimity. It may then be for the supervisor to reassure, and to point out how many possible explanations there are for seemingly contradictory results. Perhaps the data do not measure what the model demands. 
Perhaps a more sophisticated econometric methodology is required. Perhaps there are omitted variables. And so on. The student researcher may then need to be persuaded that it is perfectly OK to present weak results, so long as some awareness is shown that the analysis has limitations, and that there are many possible reasons for the seeming contradictions.

It is important to remind students of the key objective of the dissertation - namely, to showcase what they have assimilated during their degree programme. If they can show competence in applying economic analysis and (perhaps) econometric techniques in a topic area of their choice, then they are on their way to a reasonable mark. They will not be submitting their dissertation to Econometrica.

'The secret of happiness lay in limiting the aspirations.' Thomas Hardy in The Woodlanders.

\subsection{Dissertation content and structure}

Students who have spent most of their undergraduate careers solving problems and tackling exercises are likely to need specific help in constructing a coherent argument through continuous prose and appropriate structuring of material. Furthermore, the dissertation will require them to move beyond the descriptive to analysis and evaluation. These are also key skills that may only be developed through the dissertation in many economics undergraduate programmes.

There are several guides available providing advice to students on how to structure a report on a piece of economic research (e.g. Neugeboren (2005); Greenlaw (2006)).

\section{A typical structure}

\begin{tabular}{|l|l|}
\hline Introduction & pose an interesting question or problem \\
\hline Literature review & survey the literature on your topic \\
\hline Methods/data & formulate your hypothesis and describe your data \\
\hline Results & present your results with the help of graphs and charts \\
\hline Discussion & critique your method and/or discuss any policy implications \\
\hline Conclusions & summarise what you have done; pose questions for further research \\
\hline
\end{tabular}

From Neugeboren (2005)

Students need further guidance to keep an appropriate balance between the key components. The temptation is to use up too many words in the early sections in introducing the topic and describing the background. This is especially tempting in relation to some projects. For example, a student investigating a question in the context of a particular country may begin by describing the economic conditions of that country, so that the report comes to resemble something more appropriate for economic history or geography than economics. On the other hand, there may be a temptation to take some of the economic analysis for granted, thus missing the opportunity to demonstrate knowledge and understanding of economic analysis and thereby showcasing their skills to the examiner. This question of knowing what to include and what to omit is a tricky one, 
and an area in which supervisors will need to be ready to offer guidance. Another challenge is for students to be evaluative and analytic, going beyond description.

At the outset, students often find it intimidating to launch themselves on writing an 8,000 or 10,000 word report. It is important to find a way of overcoming this. One way is to encourage students to draw up a chapter plan at an early stage. This could be based on the general pattern set out above, with the students being asked to draft a few sentences describing the intended content of each chapter, and a target word count. This has the advantage of breaking the overall task into a sequence of shorter pieces of work, which may be less intimidating. Making some examples of previous dissertations available for students to consult may also be helpful, as they are able to see what can be achieved, as well as getting a feel for how to structure a long report.

\subsection{Submission}

\section{Top Tip}

Make sure there is no ambiguity about the deadline for submission and the penalties for missing it.

Another danger point comes at submission time. Be clear about the conditions under which an extension might be granted and how and whether this might be authorised. In addition, be clear about the conditions in which an extension will not be granted. For example, you might want to be explicit that extensions will not be granted for frivolous reasons or because 'my computer crashed'. There are good reasons for being strict about this. One of the skills that students derive from producing a dissertation is project management. Meeting deadlines will give students the opportunity to practise time management. A student who does not understand the need to keep back-up copies of files will have a rude awakening in the world of work. Furthermore, a student granted an extension is likely to find that there are knock-on effects in terms of exam preparation.

\subsection{Assessment}

Assessment is a crucial part of the dissertation process and entails a number of problematic issues.

It is important that students have a clear idea of what is expected of them in producing a dissertation. Unlike the problem sets and exercises that characterise much of assessment in economics, there cannot be a specific mark scheme for the dissertation. However, it is possible to provide a set of grade descriptors designed for the dissertation, showing the characteristics that markers will be looking for in allocating marks to the final product. This helps in forming student expectations and provides transparency. A sample set of descriptors is available in Appendix 3. These descriptors can be tailored to local requirements. Asking markers to highlight a copy of the descriptors for each student being assessed indicating how well they hve performed on each aspect is a good way of reaching comparability of standards across markers, and providing feedback to students afterwards. 
There is no universal agreement that this approach is desirable. It has been argued that marking to descriptors enforces too much conformity and inhibits markers from examining with their own personal and professional judgement. However, this may be an argument for framing the descriptors in such a way that they are not overly prescriptive, but yet identify the intended outcomes on which the assessment of the dissertation should be based. When large numbers of students are involved, it may be that personal and professional judgement has to be harnessed in order to ensure equity in treatment.

Another way of trying to manage student expectations is through some element of peer- or selfassessment - not necessarily as part of the summative assessment. For example, students could be encouraged to evaluate a fellow student's research proposal or presentation. Alternatively, a self-assessment checklist could be required as part of the dissertation submission, itemising key aspects of the dissertation. A sample self-assessment form is available through the Appendices.

Students may also gain confidence in their work if some portion of the summative assessment is derived from interim pieces of work, such as the research proposal, a presentation or library skills project. This can also incentivise students to manage their time and receive feedback on how they are progressing.

Achieving consistency in assessment is challenging, especially where the number of dissertations to be marked is large so that marking has to be spread between a relatively large number of staff members. Consistency is also difficult because of the wide range of dissertation topics that is possible. The use of descriptors can help here, as they are cast in general terms that do not vary across topics. The danger is that some markers will be more diligent than others in giving marks based on the descriptors. At department level, this could be monitored by constructing a spreadsheet to compare mean marks (and the standard deviation) for each pair of markers. This may help to reassure external examiners that marking has been carefully undertaken — as well as ensuring equality of treatment for students.

Where the economics dissertation can be taken by both single honours students and those following joint honours, it is important for markers to be aware of what is reasonable for particular students to produce. A politics and economics student should not be penalised for avoiding econometric work, nor should a single honours economics student be penalised for lacking background in political science.

\section{Top Tip}

The nature of the dissertation is such that it is difficult to maintain anonymity in the marking, so this is one type of assessment where double-blind marking must be retained, rather than some form of sample moderation process.

One of the issues on which practice varies between universities is the question of whether the supervisor should or should not be one of the markers of the dissertation. Some argue that the supervisor should be excluded from the assessment process in order to ensure independence of the marking, whereas others argue that the supervisor is able to identify the extent to which the 
student had received assistance as part of the supervisory process. Consistency may be more likely where marking is organised to mix up the pairings of first and second markers.

\subsection{Academic integrity}

Given the ubiquity of the internet, it has become impossible to discuss undergraduate dissertations without also discussing the greater opportunities for student plagiarism. The internet provides students with access to a vast range of material, and anecdotal evidence suggests that many students arrive at university with at best a sketchy understanding of methods of scholarship and standards of academic integrity.

Inculcating a sense of what constitutes academic integrity at an early stage in the degree programme is critical. This approach - stressing that there are expected standards for student work - is to be preferred to instructing students simply to 'avoid plagiarism'. The notion of avoiding plagiarism is almost tantamount to telling students not to get caught, whereas setting expected standards is a more positive tack to take.

The importance of academic integrity is reflected in the fact that there is a whole chapter in this Handbook by Jeremy Williams devoted to the topic. The detail of this discussion will not be repeated here, where the focus will be on academic integrity in the dissertation.

Jeremy Williams identifies three types of plagiarist. The 'lazy plagiarist' takes the work of another author and puts his or her own name to it, and may use a 'cheat' site in order to purchase a dissertation or part thereof. The 'cunning plagiarist' uses the work of another author or authors, but changes things sufficiently to avoid detection. 'Cut-and-paste' characterises this approach. The 'accidental plagiarist' does not even realise that they are plagiarising - for example, they may have taken notes on a journal article in the early stages of their research without realising that they were simply noting down the original author's words. They then construct their dissertation from those notes. In some cases, students from a Confucian tradition may believe that in reproducing the words of the experts they are paying them a compliment, and may find it culturally difficult to criticise or even amend what has been printed in a textbook. The use of anti-plagiarism software will throw up examples of all three types.

In the email survey of UK economics departments, most made use of TurnitinUK as a way of identifying whether plagiarism has taken place. The convenience of this is that a dissertation submitted via a VLE can be automatically screened for overlap with TurnitinUK's growing database. The disadvantage is that the output produced by the software requires very careful interpretation. The software produces a Similarity Index (SI), which quantifies the degree of overlap with material in the database. A high SI does not necessarily indicate plagiarism, but it does help to highlight which dissertation submissions are suspicious.

An important practical point to remember is that when students submit their dissertation they should not only be asked to sign a declaration stating that the work is their own, but also that they understand what is meant by academic integrity and that their dissertation will be checked by TurnitinUK. 


\section{Sample declaration for students to sign on submission:}

I understand that by signing the declaration below, I have read and accepted the following statements:

- I have read and understood the University's Academic Integrity Statement for Students, including the information on practice to avoid given the Statement and that in the attached submission I have worked within the expectations of this Statement.

- I am aware that failure to act in accordance with the Academic Integrity Statement for Students may lead to the imposition of penalties which, for the most serious cases, may include termination of the programme.

I consent to the University copying and distributing any or all of my work in any form and using third parties (who may be based outside the EU/EEA). This may include the use of antiplagiarism software (e.g. TurnitinUK) to verify whether my work contains plagiarised material, and for quality assurance purposes.

Perhaps more valuable than its diagnostic properties is the deterrent value of TurnitinUK. The very fact that all dissertations are to be screened may encourage students to take care in their work. If this does not suffice, then a practical demonstration may be effective.

\section{Encouraging good academic practice}

Find a brief paper written by a member of staff in the department and submit it to TurnitinUK. Then hack the article about. Include some quotations (some with, some without quotation marks), paraphrase some passages, introduce some new material. Submit the revised version to TurnitinUK.

Arrange a session for all students writing a dissertation, and show them the TurnitinUK output on the amended version. Let them see what we see as examiners. Point out the key examples of bad practice that we can readily recognise.

This exercise can have a dramatic effect. In one academic year, I (as the School's Academic Integrity Officer) had to investigate 10 breaches of academic integrity in economics dissertations. Penalties were imposed in all cases. The following year, having demonstrated the examiner's eye view of the TurnitinUK output, not one single case emerged.

More difficult to detect is where students commission a third party to produced their dissertation for them - either to order, or off the peg from subscription websites. TurnitinUK may or may not identify these cases, although I have known one case where the dissertation that had been purchased was picked up because some paragraphs from it were used as an advert on the website, and were thus caught by TurnitinUK. The risks of being caught may be lower for this form of cheating - but the penalties are likely to be more severe.

An important part of the fight for academic integrity is to make sure that all supervisors are familiar with your university's procedures for dealing with breaches of academic integrity, and 
with how to interpret the TurnitinUK output. This is a key part of ensuring consistency in supervision and equity of treatment across students. It is wise to make sure that the general principles of academic integrity are covered in joint sessions to all students, rather than this being left as part of the responsibility of the individual supervisor. Student handbooks also need to carry clear guidance on your institution's policies and procedures.

More discussion on academic integrity may be found in the Handbook chapter by Jeremy $\underline{\text { Williams }}$ and the more recent chapter by Carlos Cortinhas.

\section{An alternative to the dissertation?}

If it is accepted that all honours students should be exposed to 'current research, or equivalent advanced scholarship, in the discipline...' (QAA), then can the dissertation be avoided?

It could be argued that if we provide research-led teaching, then this in itself ensures that students will fit the bill in terms of exposure to research. But what do we mean by 'research-led teaching'? Does it mean that academic staff are given the opportunity to teach in their specialist research areas? Is that enough? How do we ensure that students engage with this process? If we cannot be sure about the answer to these questions, then is the dissertation the only solution?

To some extent, a research-led approach can be embedded within the normal curriculum. Modules can be designed in such a way as to enhance the students' ability to develop critical and evaluative thinking skills and thereby support and promote independent learning. This approach can be reinforced by a research-led approach to assessment and may be most straightforward in econometric or other quantitative methods modules, where students can be required to find, analyse and interpret their own data. A similar approach can be adopted for other modules. A development economics module can require students to prepare a report on a particular country; students could be required to evaluate a recent report from the CMA. Such exercises can encourage and engender a sense of discovery and engage students in a reflective and self-critical process. There is much more discussion or undergraduate research in economics in KimMarie Goldrick's chapter in this Handbook.

An alternative approach would be to run a seminar or tutorial-based module, in which students are required to provide critical evaluation of recent research, probably through the vehicle of appropriate journal articles. This sort of exercise can also provide students with the opportunity to develop their presentation skills, and could be part of a module that also includes sessions on aspects of research in economics. Such presentations could be given in a quasi-conference setting, if the number of students permits.

\section{Summary}

A well-organised dissertation can be the most rewarding part of the student experience. However, this may require careful thought and planning if it is not to turn into a nightmare. Here are some key points to remember as the dissertation life-cycle unfolds: 
- Think about how research training will be provided

- Ensure that students are guided towards a feasible topic

- Be aware of the legislative context

- Give early rules on word length

- Manage student and supervisor expectations of the supervisory process

- Look for a coherent way of allocating students to supervisors

- Set intermediate targets to prevent students leaving too much to the last minute

- Be aware of data issues

- Provide guidance in terms of how to structure a dissertation

- Offer clear guidelines for the assessment process, so that students know what is expected of them

- Be unambiguous in setting deadlines and the rules for extensions

- Explain academic integrity and monitor adherence

Students can benefit greatly from undertaking a dissertation. The process can capture their interest and give them confidence to engage in independent work. The finished product can be used to sell their abilities to potential employers, by showcasing their skills. Supervisors can add to the experience by making sure that students are aware of these benefits. Furthermore, students often enjoy their dissertation work.

\section{References}

Greenlaw, S. A. (2006) Doing Economics: A guide to carrying out economic research. Boston: Houghton Miffin. ISBN 9780618379835

Neugeboren, R. (2005) The Student's Guide to Writing Economics. London: Routledge. ISBN 9780415701235

"Doing a dissertation" in the 'Studying economics' section of the Economics Network website.

If you Google 'dissertations in economics' you will find many websites that claim to provide help and guidance. Some of these will be helpful to students e.g. the guide by Paul Dudenhefer; other links take you to guides provided by various Universities for their students. However, care is needed here, as students may also find offers from tutors prepared to write their dissertations at a price...

Other chapters in the Handbookfor Economics Lecturers augment this guide. In particular:

KimMarie McGoldrick, Undergraduate Research in Economics

Jeremy B. Williams, Plagiarism: Deterrence, Detection and Prevention

\section{Appendices}

1. The undergraduate dissertation in UG economics in the UK: A brief survey 
2. Risk assessment form

3. Ethics checklist

4. Grade descriptors

5. Self-assessment form 